\title{
CRITERIA FOR PROPORTIONAL REPRESENTATION
}

\section{L. BALINSKI* \\ H.P.YQUNG* \\ DECEMBER 1976}

* Graduate School and University Center, City University of New York, and International Institute for Applied Systems Analysis, Laxenburg, Austria.

This work was supported in part by the National Science Foundation under Contract MPS 75-07414 with the Graduate School of the City University of New York.

Research Reports provide the formal record of research conducted by the International Institute for Applied Systems Analysis. They are carefully reviewed before publication and represent, in the Institute's best judgment, competent scientific work. Views or opinions expressed herein, however, do not necessarily reflect those of the National Member Organizations supporting the Institute or of the Institute itself.

\section{International Institute for Applied Systems Analysis} 2361 Laxenburg, Austria 



\section{Preface}

The problem of how to make a "fair division" of resources among competing interests arises in many areas of application at IIASA. One of the tasks in the System and Decision Sciences area is the systematic investigation of different criteria of fairness and the formulation of allocation procedures based thereon.

A particular problem of fair division having wide application in governmental decision-making is the apportionment problem. An application has recently arisen in the debate over how many seats in the European Parliament to allocate to the different member countries. Discussions swirled around particular numbers, over which agreement was difficult to achieve. A systematic approach that seeks to establish bases for agreement on the criteria or "principles" for fair division should stand a better chance of acceptance in that it represents a scientific or systemanalytic approach to the problem. 



\section{Abstract}

Methods to allocate seats in proportional representation systems are investigated in terms of several underlying common-sense properties. In particular, the idea of stability is introduced, and the method of Jefferson (or d'Hondt) is characterized. 

Criteria for Proportional Representation

\section{INTRODUCTION}

There exist wholesale numbers of possible election procedures. A basic characterization has been made of these into "plurality systems" and "proportional representation systems."

In a plurality system an elector usually casts one vote for the candidate or the (party) list of candidates of his or her choice in some election district, and the candidate or list receiving a majority or plurality is elected. Such systems are based on a notion of geographical representation. Mid-nineteenth century Europe saw an increasing dissatisfaction with plurality systems as unfair to minorities, for small political parties were effectively barred from having any representation whenever their adherents were distributed throughout many single-member election districts.

This led to the idea of proportional representation which, in its pure form, has electors cast one vote for a party or party list in a multi-member district and then, by some rule, metes numbers of seats "proportionally" among the parties according to their respective vote totals. Of course, variants of both types of system exist, as do complex mixtures of both.

This paper is focused on the pure form of the proportional representation problem: voters cast a single vote for a party in a multi-member district and the question is to determine the just number of representatives due each party. Exact proportionality cannot, in general, be achieved since representation must be integral. Some "rounding" must take place. Consider, for example, the problem of Table 1 with party vote totals as given and 36 seats to be allocated. Six different possible solutions are advanced... which should be chosen?

In fact the identical problem arises under plurality systems, but in a different guise. For, usually, a nation is divided into states or provinces and each single-member election district is wholly contained in one such subdivision. How many election districts or representatives should one geographical region be allocated? This problem is known as the apportionment problem. Of course, geographical apportionment can arise in proportional representation systems too. The apportionment problem in the United States arises from interpreting the somewhat vague constitutional mandate "...Representatives... shall' be apportioned among the several states...according to their respective members." Senator Daniel Webster of Massachusetts caught the spirit of the intended solution to the apportionment problem in his definition: "To 
apportion is to distribute by right measure, to set off in just parts, to assign in due and proper proportion" [17, p. 107]. But, appearances to the contrary, an operational definition is not easily forthcoming and United States history is rich with controversies over proposed solutions and methods. It suffices to consult Table 1 to see why.

Table 1

Possible Allocations

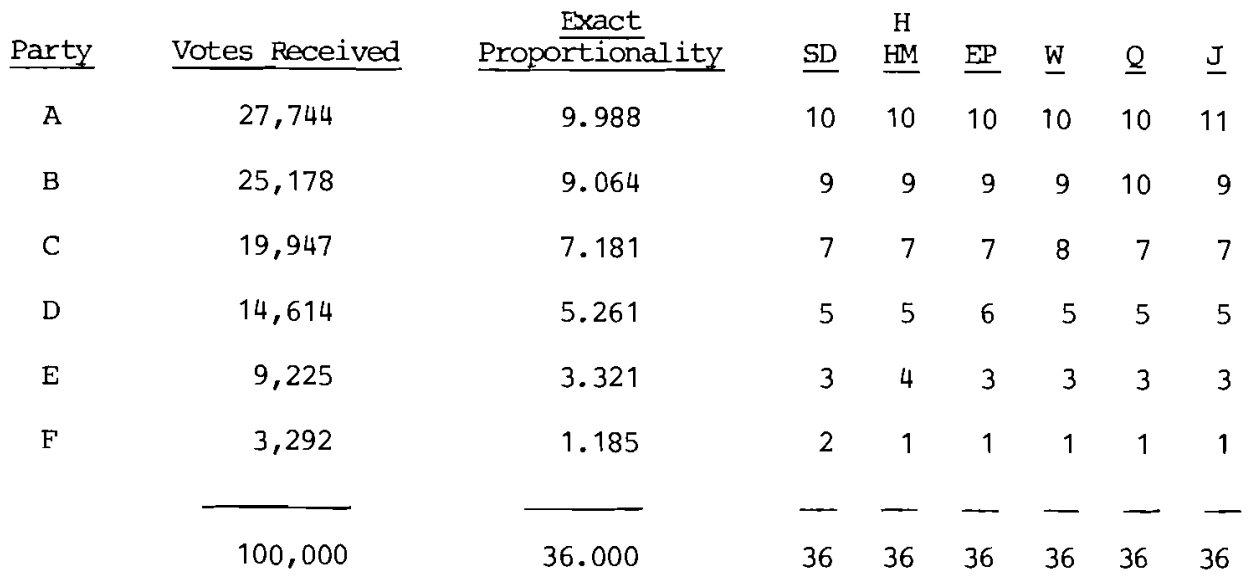

Furthermore, what seems right, just and proper in dealing with apportionment in plurality systems may or may not seem so in dealing with allocation in proportional election systems. Different sets of properties of possible methods for solving the underlying problem are suggested by the practical situation in which the mathematical allocation problem is embedded.

\section{FORMULATION}

Let $\underset{\sim}{p}=\left(p_{1}, \ldots, p_{s}\right)$ be the (positive, integer) vote totals of $s$ parties (or the number of citizens deserving representation in $s$ regions), where each $p_{i}>0$, and $h \geqq 0$ is the number of seats to be allocated (or apportioned). The problem is to find an allocation for $h$ : an s-tuple of non-negative integers $\left(a_{1}, \ldots, a_{s}\right)$ whose sum is $h$. A solution of the problem is a function $f$ which to any population vector $p$ and all $h$ associates a unique apportionment for $h, a_{i}=f_{i}(\underset{\sim}{p}, h) \geq 0$ where $\sum_{i} a_{i}=h$. 
If $\underset{\sim}{f}$ is a solution, then $\underset{\sim}{\mathrm{f}}$ will represent the function $\underset{\sim}{\mathrm{f}}$ restricted to the domain $\left(\underset{\sim}{p}, h^{\prime}\right)$ where $0 \leq h^{\prime} \leq h . f_{\sim}^{h}$ is a solution up to $\mathrm{h}$, and $\underset{\sim}{\mathrm{f}}$ is an extension of $\underset{\sim}{\mathrm{f}} \mathrm{h}$.

A specific allocation method may give several solutions, since "ties" may occur when using it, as for example when two parties have identical vote totals but must share an odd number of seats. For this reason it is useful to define an alzocation method $M$ as a non-empty set of solutions. Thus, in particular, a solution up to some given $h$ may have several different extensions in a method $M$. In the sequel only symmetric methods of allocation are considered, that is, methods in which the ordering of the parties in the list $\left(p_{1}, \ldots, p_{s}\right)$ is immaterial. This is a clearly essential property.

The choice of an allocation, or of an allocation method, cannot and should not revolve about the rival numerical results of one solution over another. Rather, the issue is to decide upon a rule that is "fair," that is, whose qualitative properties satisfy criteria or "principles" acceptable to both citizen and politician. It is as Representative E.W. Gibson said on the floor of the U.S. Congress in 1929, "The apportionment of Representatives to the population is a mathematical problem. Then why not use a method that will stand the test...?" [5].

\section{STABILITY}

Three principal methods seem to have been considered for proportional representation systems: Sainte-Lagüe's [15], d'Hondt's [8,9], and Hamilton's [7], usually known as "la répartition au plus fort reste." In the apportionment literature Sainte-Lagüe's and d'Hondt's have found their places (see [10]), under other names, in a class of five so-called "modern" [4,13] methods which, from about 1920 through 1974, were the only ones collectively considered for apportioning the United States House of Representatives.

The five "modern" methods were first grouped by E.V. Huntington in 1921 [11] via an approach to allocation (or apportionment) based on pairwise comparisons of "inequality in representation." Given vote totals $\underset{\sim}{p}=\left(p_{1}, \ldots, p_{s}\right)$ and an allocation $\underset{\sim}{a}=\left(a_{1}, \ldots, a_{s}\right)$ for $h$ consider the numbers $p_{i} / a_{i}$ and $a_{i} / p_{i}$. These represent the number of votes per representative of party $i$ and the number of representatives per vote of party $i$. If $p_{i} / a_{i}>p_{j} / a_{j}$, or $a_{i} / p_{i}<a_{j} / p_{j}$ ' or $a_{j}>a_{i}\left(p_{j} / p_{i}\right)$, or $\ldots,\left(p_{i} / a_{i}\right)\left(a_{j} / p_{j}\right)>1$, then party $j$ is better off than party $i$. Given a particular measure or test of inequality between a pair of parties such as $\left|p_{i} / a_{i}-p_{j} / a_{j}\right|$ or $\mid a_{i} / p_{i}-a_{j} / p_{j}$ it is natural to ask whether the amount of inequality can be reduced by a transfer of one seat from the better-off party to the less-well-off party. Given a measure or test $T$ an allocation is 
said to be in equilibrium if no transfer reduces the value of $T$ for any pair of parties. Of course, certain conceivable measures $T$ may not (and do not) admit equilibrium solutions for all votetotal distributions, but Huntington showed $[10,11]$ that five measures $\mathrm{T}$ do.

Huntington's approach can be developed in several ways, One is via the tests of inequality in representation mentioned above. Another (see $[13,10]$ ) is by letting $d(a)$, a divisor criterion, be any real-valued monotone-increasing function on the non-negative integers such that $d(0) \geq 0$. Given a divisor criterion $d(a), a$ divisor method $M$ of allocation is the set of solutions obtained recursively as follows:

(i) $\mathrm{f}_{i}(\underset{p}{\mathrm{p}}, \mathrm{O})=0, \quad 1 \leqq i \leqq s$.

(ii) If $a_{i}=f_{i}(\underset{p}{p}, h)$ is an $\underset{\sim}{M}-a l l o c a t i o n$ for $h$ and $k$ is some one party for which

$$
p_{k} / d\left(a_{k}\right) \geqq p_{i} / d\left(a_{i}\right) \text { for } 1 \leqq i \leqq s \quad,
$$

then

$$
\mathrm{f}_{\mathrm{k}}(\underset{\sim}{\mathrm{p}}, \mathrm{h}+1)=\mathrm{a}_{\mathrm{k}}+1, \mathrm{f}_{\mathrm{i}}(\underset{\sim}{\mathrm{p}}, \mathrm{h}+1)=\mathrm{a}_{i} \text { for } i \neq k \text {. }
$$

The meaning of such an allocation method is that the numbers $\mathrm{p}_{i} / \mathrm{d}\left(\mathrm{a}_{i}\right)$ represent some measure of the "priority" of a party to receive one more seat, the next seat being given to the most deserving party. The divisor function d(a) thus represents some sort of "weighting" of the current number of seats the party has.

The five "modern" methods proposed by Huntington are divisor methods, and their various names, associated tests of inequality and divisor criteria are given in Table 2 below. Huntington himself argued strongly and effectively for the method he called Equal Propoxtions. It is in equilibrium for the measure of inequality which is the relative difference* between the pair of numbers $p_{i} / a_{i}$ and $p_{j} / a_{j}$, and also between $a_{i} / p_{i}$ and $a_{j} / p_{j}$. This method is now the law for apportionirg the U.S. House of Representatives [14].

${ }^{*}$ The relative difference between $x$ and $y$ is $|x-y| /$ min $(x, y)$. 
Table 2. Huntington's five methods.

Method

In Equilibrium for Test $\mathrm{T}$

Divisor Criterion

(where $p_{i} / a_{i} \geq p_{j} / a_{j}$ )

$\mathrm{d}(\mathrm{a})$

\begin{tabular}{|c|c|c|}
\hline Smallest Divisors (SD) & $\mathrm{T}_{1}: a_{j}-a_{i}\left(p_{j} / p_{i}\right)$ & $\mathrm{a}$ \\
\hline Harmonic Mean (년) & $\mathrm{T}_{2}: \quad \mathrm{p}_{i} / \mathrm{a}_{i}-\mathrm{p}_{j} / \mathrm{a}_{j}$ & $2 a(a+1) /(2 a+1)$ \\
\hline Equal Proportions (EP) & $\mathrm{T}_{3}: \quad\left(\mathrm{p}_{i} a_{j} / \mathrm{p}_{j} \mathrm{a}_{i}\right)-1$ & $(a(a+1))^{1 / 2}$ \\
\hline $\begin{array}{l}\text { Webster }(W) \\
\text { or Major Fractions } \\
\text { or Sainte-Laglbe Formula }\end{array}$ & $\mathrm{T}_{4}: \mathrm{a}_{j} / \mathrm{p}_{j}-a_{i} / \mathrm{p}_{i}$ & $(a+1 / 2)$ \\
\hline $\begin{array}{l}\text { Jefferson }(\mathrm{J}) \\
\text { or Greatest Divisors } \\
\text { or d'Hondt } \\
\text { or plus forte moyenne }\end{array}$ & $T_{5}: a_{j}\left(p_{i} / p_{j}\right)-a_{i}$ & $a+1$ \\
\hline
\end{tabular}

The method of equal proportions (EP) necessarily first gives to each party one seat. As an example of a divisor method in use, Table 3 below gives EP allocations to parties for the example of Table 1 for a house size h ranging from 6 to 16 seats.

D'Hondt's method $[8,9]$, or "la répartition à la plus forte moyenne," also called in the apportionment literature "the method of greatest divisors," was in fact first proposed by Thomas Jefferson [12] in 1792 and has therefore been called Jefferson's method J [3]. Sainte-Lagüe's method [15], also called in the apportionment literature "the method of major fractions," was in fact first suggested in embryonic form by Daniel Webster [17] in 1832 and has therefore been called the webster method $W$ [3]. A particular variant of $\underset{\sim}{W}$ is the modified method of odd numbers (see, e.g., [6]) used in some scandinavian countries. It is defined by: $d(O)=7 / 10$ (instead of $d(0)=1 / 2$ ), and otherwise the divisors are identical with those of $\underset{\sim}{W}, d(a)=a+1 / 2$.

It is an interesting historical note that sainte-Lagüe [15] came upon the Webster method quite independently via the idea of minimizing a total measure of the inequality of an allocation. He proposed that an allocation should minimize

$$
\sum_{i} p_{i}\left(\frac{h}{p}-\frac{a_{i}}{p_{i}}\right)^{2}
$$


since in a perfect allocation $\mathrm{h} / \mathrm{p}=\mathrm{a}_{\mathrm{i}} / \mathrm{p}_{\mathrm{i}}$ for all $\mathrm{i}$. The webster method provides solutions which do this. In the same paper Sainte-Lagüe suggests in words (though not in symbols) that one could be interested in minimizing

$$
\sum_{i} a_{i}\left(\frac{p}{h}-\frac{p_{i}}{a_{i}}\right)^{2},
$$

but that "one is led to a more complex rule." In fact, this gives precisely the method of equal proportions.

Table 3. Sample EP allocations.

\begin{tabular}{c|cccccc} 
Party & A & B & C & D & $E$ & $F$ \\
Vote Total & 27,744 & 25,178 & 19,947 & 14,614 & 9,225 & 3,292 \\
\hline House size & & & & & & \\
6 & 1 & 1 & 1 & 1 & 1 & 1 \\
7 & 2 & 1 & 1 & 1 & 1 & 1 \\
8 & 2 & 2 & 1 & 1 & 1 & 1 \\
9 & 2 & 2 & 2 & 1 & 1 & 1 \\
10 & 3 & 2 & 2 & 1 & 1 & 1 \\
11 & 3 & 2 & 2 & 2 & 1 & 1 \\
12 & 3 & 3 & 2 & 2 & 1 & 1 \\
13 & 3 & 3 & 3 & 2 & 1 & 1 \\
14 & 4 & 3 & 3 & 2 & 1 & 1 \\
15 & 4 & 4 & 3 & 2 & 1 & 1 \\
16 & 4 & 4 & 3 & 2 & 2 & 1 \\
$\vdots$ & $\vdots$ & $\vdots$ & $\vdots$ & $\vdots$ & $\vdots$ & $\vdots$ \\
36 & 10 & 9 & 7 & 6 & 3 & 1 \\
\hline
\end{tabular}

It is useful to know that there is a "local" criterion by which to verify whether allocation belongs to a divisor method. 
Lemma. $\underset{\sim}{a}=\left(a_{1}, \ldots, a_{s}\right)$ is an allocation for $h$ of a divisor method with divisor criterion $d(a)$ if and only if

$$
\min _{j} p_{j} / d\left(a_{j}-1\right) \geqq \max _{i} p_{i} / d\left(a_{i}\right)
$$

This is immediate by definition. $\square$

Parties in proportional representation systems are dynamic. They may group together for electoral purposes, but they also may splinter. It is likely that the behavior of parties will be influenced by the mathematical consequences of their coalescing as versus splintering. Specifically, it is pertinent to ask how the number of seats allocated by a method $M$ to the joint vote total of two parties coalesced into one compares with the seats allocated by $M$ to the two parties separately. Consider a symmetric method $M$ and a problem with vote totals $p$ in which some party has $\mathrm{p}^{*}$ votes and another $\overline{\mathrm{p}}$ votes; and cons̃ider the result of coalescing the star- and the bar-party into one party with $\mathrm{p}^{*}$ $+\bar{p}$ votes, keeping all other party vote totals the same. Let $\underset{\sim}{f} \in \underset{\sim}{M}$ be a solution in which a* and $\bar{a}$ are the number of seats allocated to the star- and the bar-party, respectively, in an allocation for $h$. Then $M$ is said to be stable if there exists an allocation for $h$ in which the number $b$ of seats allocated to the coalesced party satisfies $a^{*}+\bar{a}-1 \leqq b \leqq a^{*}+\bar{a}+1$.

Theorem 1. A divisor method $\underset{\sim}{\mathrm{M}}$ with divisor criterion d(a) satisfying

$$
d\left(a_{1}+a_{2}\right) \leqq d\left(a_{1}\right)+d\left(a_{2}\right) \leqq d\left(a_{1}+a_{2}+1\right)
$$

is stable.

Proof: Suppose that an allocation for $h$ of a problem specified by the vote totals $\underset{\sim}{p}=\left(p_{1}, \ldots, p_{s}\right)$ is $\underset{\sim}{a}=\left(a_{1}, \ldots, a_{s}\right)$ and that parties 1 and 2 form a coalition having vote total $p_{1}+p_{2}$. Then we show that if $\left(a_{1}+a_{2}, a_{3}, \ldots, a_{5}\right)$ is not an allocation for $h$ then there exists one that gives the coalition either

$$
\begin{aligned}
a_{1}+a_{2}-1 \text { or } a_{1}+a_{2}+1 \text { seats. } \\
\quad \text { If } a_{1}+a_{2} \text { is not a solution, then by the Lemma }
\end{aligned}
$$

$\min \left\{\left(p_{1}+p_{2}\right) / d\left(a_{1}+a_{2}-1\right), \min _{i \neq 1,2} p_{i} / d\left(a_{i}-1\right)\right\} \underset{\neq}{\max }\left\{\left(p_{1}+p_{2}\right) / d\left(a_{1}+a_{2}\right), \max _{j \neq 1,2} p_{j} / d\left(a_{j}\right)\right\}$. 
Thus since a satisfies (1), either

(3) $\left(p_{1}+p_{2}\right) / d\left(a_{1}+a_{2}-1\right)<\max _{j \neq 1,2} p_{j} / d\left(a_{j}\right)=p_{k} / d\left(a_{k}\right)=\lambda(k \neq 1,2)$

or

(4) $\left(p_{1}+p_{2}\right) / d\left(a_{1}+a_{2}\right)>\min _{i \neq 1,2} p_{i} / d\left(a_{i}-1\right)=p_{\ell} / d\left(a_{\ell}-1\right)=\delta \quad(\ell \neq 1,2)$. Before proceeding, notice that if $s_{i}, v_{i} \geq 0(i=1,2)$ then $\max \left\{s_{1} / v_{1}, s_{2} / v_{2}\right\} \geq\left(s_{1}+s_{2}\right) /\left(v_{1}+v_{2}\right) \geq \min \left\{s_{1} / v_{1}, s_{2} / v_{2}\right\}$.

This inequality is used repeatedly.

Consider the first case (3). From (2) we have

$$
\begin{aligned}
\left(\mathrm{p}_{1}+\mathrm{p}_{2}\right) / \mathrm{d}\left(\mathrm{a}_{1}+\mathrm{a}_{2}-2\right) & \geqq\left(\mathrm{p}_{1}+\mathrm{p}_{2}\right) /\left(\mathrm{d}\left(\mathrm{a}_{1}-1\right)+\mathrm{d}\left(\mathrm{a}_{2}-1\right)\right) \geq \min \left\{\mathrm{p}_{1} / \mathrm{d}\left(\mathrm{a}_{1}-1\right), \mathrm{p}_{2} / \mathrm{d}\left(\mathrm{a}_{2}-1\right)\right\} \\
& \geqq \max _{i} \mathrm{p}_{i} / \mathrm{d}\left(\mathrm{a}_{i}\right) \geqq \lambda
\end{aligned}
$$

and find

$$
\begin{aligned}
& \min \left\{\left(p_{1}+p_{2}\right) / d\left(a_{1}+a_{2}-2\right), p_{k} / d\left(a_{k}\right), \min _{i \neq 1,2, k} p_{i} / d\left(a_{i}-1\right)\right\} \geqq \lambda \\
& \geq \max \left\{\left(p_{1}+p_{2}\right) / d\left(a_{1}+a_{2}-1\right), p_{k} / d\left(a_{k}+1\right), \max _{i \neq 1,2, k} p_{i} / d\left(a_{i}\right)\right\},
\end{aligned}
$$

showing that $\left(a_{1}+a_{2}-1, a_{3}, \ldots, a_{k}+1, \ldots, a_{s}\right)$ is an allocation for $h$. on the other hand, consider (4). Since by (2)

$$
\begin{aligned}
\left(p_{1}+p_{2}\right) / d\left(a_{1}+a_{2}+1\right) & \leqq\left(p_{1}+p_{2}\right) /\left(d\left(a_{1}\right)+d\left(a_{2}\right)\right) \leq \max \left(p_{1} / d\left(a_{1}\right), p_{2} / d\left(a_{2}\right)\right\} \\
& \leq \min _{j} p_{j} / d\left(a_{j}-1\right) \leq \delta,
\end{aligned}
$$


we find

$$
\begin{aligned}
& \min \left\{\left(p_{1}+p_{2}\right) / d\left(a_{1}+a_{2}\right), p_{\ell} / d\left(a_{\ell}-2\right) \min _{i \neq 1,2, \ell} p_{i} / d\left(a_{i}-1\right)\right\} \geq \delta \\
& \geq \max \left\{\left(p_{1}+p_{2}\right) / d\left(a_{1}+a_{2}+1\right), p_{\ell} / d\left(a_{\ell}-1\right), \max _{j \neq 1,2, \ell} p_{i} / d\left(a_{j}\right)\right\} ，
\end{aligned}
$$

showing that $\left(a_{1}+a_{2}+1, a_{3}, \ldots, a_{\ell}-1, \ldots, a_{s}\right)$ is an allocation for $h .0$

Corollary. Hamilton's five divisor methods are stable.

The method that has been and is most often proposed for proportional representation happens to be the seemingly most natural one. Although known by several names, including "la répartition au plus fort reste" and "Vinton's method of 1850," it was apparently first proposed by Alexander Hamilton [7] in 1792 and has therefore been called the Hamilton method $H$ [3]. We define the exact quota of party $j$ to be $q_{j}=q_{j}(\underset{\sim}{p}, h) \stackrel{\sim}{=} p_{j} h / \sum_{i} p_{i}$. It is the exactly proportional number of seats deserved by party $j$ and the number that one would wish to allocate to $j$ were it integral. Otherwise, each party should, it seems, receive at least as many seats as $\left\langle q_{j}\right\rfloor$ (the largest integer less than or equal to $q_{j}$ ). This motivates the allocations of the Hamilton method: First, give to each party $\left.i \mid q_{i}\right\rfloor$ seats; then, order the parties by their fractional remainders $d_{j}=q_{j}-\left\lfloor q_{j}\right\rfloor \geq 0$ in a priority list $\mathrm{d}_{j_{1}} \geqq \cdots \geqq \mathrm{d}_{j_{s}}$. Second, give one additional seat to each of the first $\left.h-\sum l q_{j}\right\rfloor$ parties on the list. If there are ties then there exist distinct arrangements of the priority list and, hence, possibly several solutions. In fact, this method, under the name of the Vinton method of 1850, was adopted as the solution to the apportionment problem for the U.S. House of Representatives for the censuses of 1850 through 1900 .

Theorem 2. The Hamilton method is stable.

Proof: Consider any two parties, say $i=1,2$, and suppose that in a particular problem party $i$ has an exact quota $q_{i}=n_{i}$ $+r_{i}, n_{i} \geq 0$ integer and $0 \leqq r_{i}<1$, and let $a_{i}$ be their allocations at $h$. Then for the problem in which parties 1 and 2 form a coalition, its exact quota for $h$ is. $q_{1}+q_{2}=n_{1}+n_{2}+r_{1}+r_{2}$. Let $b$ be the number of seats given the coalition by the Hamilton method.

We consider several cases. First, if $b=n_{1}+n_{2}$ then $r_{1}+$ $r_{2}<1$, implying that the same total number of parties is rounded 
up in both problems. If $r_{1}, r_{2}>0$ then it must be that $a_{i}=n_{i}$ $(i=1,2)$. For otherwise one of the two parties would have a remainder $r_{i}$ high enough in the list to warrant an extra seat while $r_{1}+r_{2}>r_{1}, r_{2}$ is not high enough, which cannot be. If $r_{1}=0$ then $a_{1}=n_{1}$ and $a_{2}=n_{2}$ or $a_{2}=n_{2}+1$; in either case the criterion for stability is satisfied.

If $b=n_{1}+n_{2}+1$, then since $a_{i}=n_{i}$ or $n_{i}+1$ there is nothing more to show. If $b=n_{1}+n_{2}+2$, then $r_{1}+r_{2}>1$. Suppose stability is not satisfied, i.e., that $a_{i}=n_{i}(i=1,2)$. Then for some party $k \neq 1,2, r_{1}+r_{2}-1 \geq r_{k}$ while $r_{1} \leqq r_{k}$ and $\mathrm{r}_{2} \leqq \mathrm{r}_{\mathrm{k}}$. Thus $2 \mathrm{r}_{\mathrm{k}}-1 \geqq \mathrm{r}_{\mathrm{k}}$ and $\mathrm{r}_{\mathrm{k}} \geqq 1$, a contradiction. $\square$

\section{MONOTONICITY AND CONSISTENCY}

The Hamilton method came under sharp criticism and was subsequently abandoned by the U.S. Congress for, in 1881, it chanced to admit the not so congenial "Alabama paradox" [16]. Consider the vote totals of Table 1 and apply $\mathrm{H}$ to apportion 37 and 38 seats (Table 4): parties $D$ and $E$ both lose a seat as the total number of seats to be allocated increases! For the data of the 1880

Table 4 .

\begin{tabular}{l|cccccc|c} 
Party & $\mathrm{A}$ & $\mathrm{B}$ & $\mathrm{C}$ & $\mathrm{D}$ & $\mathrm{E}$ & $\mathrm{F}$ & Totals \\
Vote Total & 27,744 & 25,178 & 19,947 & 14,614 & 9,225 & 3,292 & 100,000 \\
\hline Exact quota 35 & 9.711 & 8.812 & 6.982 & 5.115 & 3.229 & 1.152 & 35 \\
H allocation 35 & 10 & 9 & 7 & 5 & 3 & 1 & 35 \\
\hline Exact quota 36 & 9.998 & 9.064 & 7.181 & 5.261 & 3.321 & 1.185 & 36 \\
H allocation 36 & 10 & 9 & 7 & 5 & 4 & 1 & 36 \\
\hline Exact quota 37 & 10.265 & 9.316 & 7.380 & 5.407 & 3.413 & 1.218 & 37 \\
H allocation 37 & 10 & 9 & 7 & 6 & 4 & 1 & 37 \\
\hline Exact quota 38 & 10.543 & 9.568 & 7.580 & 5.533 & 3.506 & 1.251 & 38 \\
H allocation 38 & 11 & 10 & 8 & 5 & 3 & 1 & 38 \\
\hline Exact quota 39 & 10.820 & 9.819 & 7.779 & 5.699 & 3.598 & 1.284 & 39 \\
H allocation 39 & 11 & 10 & 8 & 6 & 3 & 1 & 39 \\
\hline
\end{tabular}


Census, Alabama suffered by dropping from 8 to 7 seats as $h$ increased from 299 to 300 . This phenomenon is not rare numerically. For example, the populations of the states used to apportion the U.S. Congress in 1901 gave rise to many similar occasions. Between $\mathrm{h}=381$ and $\mathrm{h}=391$, Maine changed between 2 and 3 seats six times and led a Representative of that state to exclaim "...it does seem as though mathematics and science has combined to make a shuttlecock* and battledore* of the state of Maine in connection with the scientific basis upon which this bill is presented" ( 8 January 1901).

An evident property of any allocation method is that the number of seats accorded to any party not decrease if the house size increases. A method $\underset{\sim}{M}$ is said to be monotone if for any $\underset{\sim}{M}$-solution $\underset{\sim}{f}$ and all $\underset{\sim}{\mathrm{p}}, \mathrm{h}$

$$
f_{i}(p, h+1) \geq f_{i}(p, h), i=1, \ldots, s .
$$

H fails to satisfy this test and hence was emphatically rejected.

Divisor methods are obviously monotone. Indeed, it was for this reason that they were formulated. Notice, moreover, that divisor methods have a certain inner regularity; namely, the decision as to which party of any pair most deserves the extra seat as the house size is increased by 1 depends only upon the populations and seats already allocated to those parties singly, and not on the vote vector $\underset{\sim}{p}$ or the vector of seats so far allocated $\underset{\sim}{ }$.

More generally, consider a method $M$ and suppose that it has a solution $f$ allocating to a party with ${ }^{2}$ * votes a* seats and to a party with $\bar{p}$ votes $\bar{a}$ seats in a house $h$, while $f$ allocates to the star-party $a^{*}+1$ seats, and to the bar-party $\bar{a}$ seats in a house $\mathrm{h}+1$. Then the star-party is said to have weak priority at that point, and this is written $\left(\mathrm{p}^{*}, \mathrm{a}^{*}\right) \propto(\overline{\mathrm{p}}, \overline{\mathrm{a}})$. A natural criterion for any method is that the claims of any two parties for an extra seat should depend only on their respective vote totals and allocations. Specifically, if for some other allocation problem with votes $\mathrm{p}^{\prime}$ there are parties having votes $\mathrm{p}^{*}$ and $\bar{p}$ that are allocated, by ${ }^{2}$ a solution of $\mathcal{M}^{\prime} a^{*}$ and $\bar{a}$ seats respectively, and also $(\overline{\mathrm{p}}, \overline{\mathrm{a}}) \leqslant\left(\mathrm{p}^{*}, \mathrm{a}^{*}\right)$, then the parties are said to be tied, and this is written $\left(\mathrm{p}^{*}, \mathrm{a}^{*}\right) \sim(\overline{\mathrm{p}}, \overline{\mathrm{a}})$. A method is said to be consistent if it treats tied parties equally, that is, if ( $\left.\mathrm{p}^{*}, \mathrm{a}^{*}\right)$ $\sim(\bar{p}, \bar{a})$ implies $f^{h}$ has both an extension giving the star-party $a^{*}+1$ seats at $\tilde{h}+1$, and an extension giving the bar-party $\bar{a}+1$ seats at $h+1$. Any two parties will naturally compare their resultant numbers of seats: a change in priorities could not but be viewed as conflicting with common sense. Note that any consistent method is automatically symmetric.

*The projectile and racquet, respectively, in badminton. 
Divisor methods are clearly consistent. The Hamilton method is not. For consider the $\mathrm{H}$ allocations of Table 4. Parties D and E receive 5 and 3 seats, réspectively, for $\mathrm{h}=35$ and uniquely received 5 and 4 for $h=36$. However, they receive 5 and 3 , respectively, for $h=38$, and uniquely 6 and 3 for $h=39$. This provides one more argument against the Hamilton method.

Let $r(p, a)$ be any real-valued function of two real variables called a rank-index (possibly including $\pm \infty$ for certain values of $p$ and $a$ ). Given a rank-index, a (generalized) Huntington method [3] of allocation $\underset{M}{M}$ is the set of all solutions $\underset{\sim}{f}$ obtained recursively as follows:

$$
f_{i}(p, 0)=0, \quad 1 \leqq i \leqq s \quad
$$

(ii) if $a_{i}=f_{i}(\underset{\sim}{p}, h)$ is an $\underset{\sim}{M}$ allocation for $h$ and $k$ is some one party for which

$$
r\left(p_{k}, a\right) \geq r\left(p_{i} a_{i}\right) \text { for } 1 \leqq i \leqq s,
$$

then

$$
f_{k}(\underline{\sim}, h+1)=a_{k}+1, \quad f_{i}(\underset{\sim}{p}, h+1)=a_{i} \text { for } i \neq k \text {. }
$$

Huntington methods are a direct generalization of divisor methods. They are clearly monotone and consistent. Less obvious is

Theorem 3 [2]. Any consistent, monotone method of allocation is a Huntington method.

There do, nevertheless, exist rather dubious Huntington methods. For example, take $r(p, a)=a / p$. Then the first party to receive one seat must necessarily receive all. We will say that a method is balanced if two parties having identical vote totals are always allocated numbers of seats that differ by at most 1. Divisor methods are balanced; so is the Hamilton method. But Huntington methods in general are not. A method that is not balanced could not be countenanced.

\section{COALITIONS AND SCHISMS}

In the context of proportional representation it is important to ask, not only whether methods are stable, but also whether they tend to encourage parties to merge or to splinter. For political stability it would usually be considered desirable to have methods of allocation that encourage parties to coalesce by assuring that this would never cost seats, but could in fact result in an increase in the total number of seats allocated jointly to the parties. 
To make these ideas precise, consider a symetric stable method $\underset{\sim}{M}$ and a problem with vote totals $\mathrm{p}$ in which one party has p* votes and another $\bar{p}$ votes; and considẽr the result of coalescing the star- and the bar-party into one party with $\mathrm{p}^{*}+\overline{\mathrm{p}}$ votes, keeping all other party vote totals the same. Let $\underset{\sim}{f} \in \underset{\sim}{M}$ be a solution in which $\mathrm{a}^{*}$ and $\overline{\mathrm{a}}$ are the number of seats allocated to the star- and the bar-party, respectively, in an allocation for $h$. Then $\underset{\sim}{M}$ is said to encourage coalitions if there exists an allocation giving the coalesced party $b$ seats with $b \geqq a^{*}+\bar{a}$, and to encourage schisms if $\mathrm{b} \leq \mathrm{a}^{*}+\overline{\mathrm{a}}$.

A method $\underset{\sim}{M}$ is said to be unique satisfying certain properties if any other sêt $M^{\prime}$ of allocation solutions with the same properties is also a set of solutions by $\underset{\sim}{\mathbb{M}}$, that is, $\underset{\sim}{M} \subseteq \underset{\sim}{M}$.

Theorem 4. The Jefferson method $\mathrm{J}$ is the unique consistent, monotone and balanced method that encourages coalitions.

Viewed in this light the Jefferson method presents strong credentials for being adopted in a proportional representation system. Sainte-Lagüe appears to have realized the tendency of $\mathrm{J}$ to encourage coalitions, but he gave no proofs and his statement has the curiosity of referring to a comparison: "In comparing the two rules, one can show that the d'Hondt rule ( $\underset{\sim}{J}$ ) favors the grouping of parties which, by coalescing, may receive more seats; whereas the method of least squares $(\underset{\sim}{)}$ ) favors neither groupings nor schisms," [15, p. 378].

Proof: Since $\underset{J}{J}$ is a divisor method, it is easily seen that it is consistent, monotone, and balanced. To show that $\mathrm{J}$ encourages coalitions, let a be a Jefferson allocation of $h$ for given vote totals $p_{\sim}$, and consider the vote totals $\left(p_{1}+p_{2}, p_{3}, \ldots, p_{s}\right)$ in which parties 1 and 2 have formed a coalition. If $\left(a_{1}+a_{2}, a_{3}, \ldots, a_{s}\right)$ is not a solution, then by the Lemma,

$$
\min \left\{\left(p_{1}+p_{2}\right) /\left(a_{1}+a_{2}\right), \min _{i \neq 1,2} p_{i} / a_{i}\right\} \neq \max \left\{\left(p_{1}+p_{2}\right) /\left(a_{1}+a_{2}+1\right), \max _{j \neq 1,2} p_{j} /\left(a_{j}+1\right)\right\}
$$

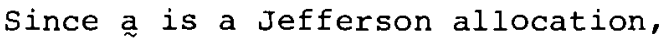

$$
\left(p_{1}+p_{2}\right) /\left(a_{1}+a_{2}\right) \geqq \min \left\{p_{1} / a_{1}, p_{2} / a_{2}\right\} \geqq \max _{j \neq 1,2} p_{j} /\left(a_{j}+1\right),
$$

so the only reason (5) can hold is that

$$
\left(p_{1}+p_{2}\right) /\left(a_{1}+a_{2}+1\right)>\min _{i \neq 1,2} p_{i} / a_{i}=p_{\ell} / a_{\ell}=\delta \quad(\ell \neq 1,2) \quad .
$$


On the other hand,

$$
\begin{aligned}
\left(p_{1}+p_{2}\right) /\left(a_{1}+a_{2}+2\right) & \leqq \max \left\{p_{1} /\left(a_{1}+1\right), p_{2} /\left(a_{2}+1\right)\right\} \\
& \leqq \min _{j} p_{j} / a_{j} \leqq \delta
\end{aligned}
$$

hence, combining (6) and (7),

$$
\begin{aligned}
& \min \left\{\left(p_{1}+p_{2}\right) /\left(a_{1}+a_{2}+1\right), p_{\ell} /\left(a_{\ell}-1\right), \min _{j \neq 1,2, \ell} p_{j} / a_{j}\right\} \geqq \delta \\
& \geq \max \left\{\left(p_{1}+p_{2}\right) /\left(a_{1}+a_{2}+2\right), p_{\ell} / a_{\ell}, \max _{j \neq 1,2, \ell} p_{j} /\left(a_{j}+1\right)\right\},
\end{aligned}
$$

which shows (by the Lemma) that $\left(a_{1}+a_{2}+1, a_{3}, \ldots, a_{\ell}-1, \ldots, a_{s}\right)$ is a Jefferson allocation for $h$.

Conversely, let $M$ be any method having the stated properties. Then $\underset{\sim}{M}$ is a Huntington method, hence (by Theorem 3 ) has a rankindex $r(p, a)$. Since $M$ is balanced, $r(p, a)>r(p, a+1)>\ldots>$ $r(p, a+k)$ for any integer $k>0$. It will be shown that $r(p, a)$ is equivalent to $\mathrm{p} /(\mathrm{a}+1)$.

As a first step we show that $r(p, a)=r(n p, n a+n-1)$ for all integers $n \geq 1$. Consider the vote vector $\underset{\sim}{p}=\left(p_{1}, \ldots, p_{n+1}\right)=$ $(p, \ldots, p)$ and house size $h=(n+1) a+n$ for any integer $a \geqq 0$. Since $M$ is balanced we can assume an allocation for $h(a, a+1, \ldots$, $a+1)$. Now consider the vote vector $(p, n p)$ and a corresponding two-party allocation for $h$, say $(x, y)$. By coalition encouragement there exists a solution with $y \geq n a+n$ and hence $x \leq a$. There is a lowest $h^{\prime} \leq h$ such that the second party (with vote total $\mathrm{np}$ ) has $\mathrm{y}$ seats and the first some $\mathrm{x}-\mathrm{k}$ seats, $\mathrm{k} \geq 0$. Thus $r(n p, y-1) \geqq r(p, x-k) \geqq r(p, x)$ and so

$$
r(p, a) \leqq r(p, x) \leqq r(n p, y-1) \leqq r(n p, n a+n-1)
$$

Consider, instead, the vote vector $\left(p_{1}, \ldots, p_{2 n}\right)=(p, \ldots, p)$ and house size $h=2 n a+n . \quad M$ balanced implies that it must have an allocation of form $(a+1, \ldots, a+1, a, \ldots, a)$ with $a_{i}=a+1$ for $1 \leqq i \leqq n$ and $a_{i}=a$ for $n+1 \leqq i \leqq 2 n$. Now consider the vote totals $\left.\left(p_{1}, \ldots, p_{n}, p_{n+1}\right)=p, \ldots, p, n p\right)$ and let $\left(x_{1}, \ldots, x_{n}, y\right)$ be an allocation of $\underset{\sim}{M}$ for $h=2 n a+n$. Since $\underset{\sim}{M}$ is stable, $y \leq n a+n-1$, 
and thus there is an $i$ with $1 \leqq i \leqq n$ having $x_{i} \geq a+1$. There is a lowest $h^{\prime} \leqq h$ such that party $i$ has $x_{i}$ seats and the $(n+1)$ st party (with vote total $n p$ ) some $y-k$ seats, $k \geqq 0$. Thus $r\left(p, x_{i}-1\right) \geq r(n p, y-k) \geq r(n p, y)$ and so

$$
r(p, a) \geqq r\left(p, x_{i}-1\right) \geqq r(n p, y) \geqq r(n p, n a+n-1)
$$

which, with $(8)$, shows that $r(p, a)=r(n p, n a+n-1)$.

To complete the proof suppose $p /(a+1)=p^{\prime} /\left(a^{\prime}+1\right)$. Then

$$
r(p, a)=r\left(p^{\prime} p, p^{\prime} a+p^{\prime}-1\right)=r\left(p p^{\prime}, p a^{\prime}+p-1\right)=r\left(p^{\prime}, a^{\prime}\right),
$$

implying that $r(p, a)=R(p /(a+1))$ for some function $R$. $R$ is order-preserving, for suppose $p /(a+1)<p^{\prime} /\left(a^{\prime}+1\right)$. Then pa' + $p<p^{\prime} a+p^{\prime}$, and

$$
\begin{aligned}
R(p /(a+1)) & =R\left(p p^{\prime} /\left(p^{\prime} a+p^{\prime}\right)\right)=r\left(p p^{\prime}, p^{\prime} a+p^{\prime}-1\right) \\
& \left.<r\left(p^{\prime} p, p a^{\prime}+p-1\right)=R\left(p^{\prime} p /\left(p a^{\prime}+p\right)\right)=R\left(p^{\prime} / a^{\prime}+1\right)\right),
\end{aligned}
$$

which completes the proof.u

The method of smallest divisors is, in a certain sense, "symmetric" with J. This suggests

Theorem 5. The method of smallest divisors SD is the unique consistent, monotone and balanced method that encourages schisms.

Proof: We first show that $r(p, a)=r(n p, n a)$ for all integers $\mathrm{n} \geqq 1$. Consider the vote vector $\left(\mathrm{p}_{1}, \ldots, \mathrm{p}_{\mathrm{n}+1}\right)=(\mathrm{p}, \ldots, \mathrm{p})$ and house size $h=n a+a+1$ for any integer $a \geq 0$. M balanced implies that an allocation at $h$ has form $(a+1, \bar{a}, \ldots, a)$. Now consider $(p, n p)$ and any allocation of $\underset{\sim}{M}(x, y)$. By schism encouragement there exists a solution with $\mathrm{y}^{\sim} \leqq$ na and hence $\mathrm{x} \geq a+1$. An argument identical to that given in Theorem 4 shows that for $k \geq 0$

$$
r(p, a) \geqq r(p, x-1) \geqq r(n p, y-k) \geqq r(n p, y) \geqq r(n p, n a) \quad
$$

Consider, instead, the vote vector $\left(p_{1}, \ldots, p_{2 n}\right)=(p, \ldots, p)$ and house size $h=2 n a+n$. M balanced implies $(a, \ldots, a, a+1, \ldots$, $a+1)$ is an allocation of $h$. Now consider the vote vector $\left(p_{1}, \ldots\right.$ $\left.p_{n}, p_{n+1}\right)=(p, \ldots, p, n p)$. Since $M$ is stable there exists an 
allocation $\left(x_{1}, \ldots, x_{n}, y\right)$ with $y \geqq n a+1$ and so there must be some $i, 1 \leqq i \leqq n$, with $x_{i} \leqq a$. So, we obtain as before

$$
r(p, a) \leqq r\left(p, x_{i}\right) \leqq r(n p, y-1) \leqq r(n p, n a) \quad,
$$

which, with $(10)$, shows that $r(p, a)=r(n p, n a)$. The proof that $\mathrm{SD}$ results from the stated properties is completed by showing that $\mathbf{r}(\mathrm{p}, \mathrm{a})=\mathrm{R}(\mathrm{p} / \mathrm{a})$ for some order-preserving function $\mathrm{R}$, as in the proof of Theorem 4 .

That SD is consistent, monotone and balanced is clear. To show that $\tilde{i t}$ encourages schisms requires an argument that precisely parallels the corresponding part of the proof of Theorem 4.0

\section{SATISFYING QUOTA}

The ideal, exactly proportional number of seats "due" party $j$ is the exact quota $q_{j}(p, h)=p_{j} h / \sum_{i} p_{i}$. Given $\underset{\sim}{p}$ and $h$, if $q_{i}$ $=q_{i}(p, h)$ is integer for all $i$ then $a_{i}=q_{i}$ is a seemingly perfect solution. In general, of course, we cannot expect any of the exact quotas to be integer. On the other hand, it is natural to require that no party receive more seats than the result of "rounding" $q_{i}$ up $\left(\left[q_{i}\right]_{\text {, the smallest integer greater than or }}\right.$ equal to $q_{i}$ ) and no less than the result of "rounding" $q_{i}$ down $\left(\left\lfloor q_{i}\right\rfloor\right.$, the largest integer less than or equal to $\left.q_{i}\right)$. A method is said to satisfy quota if all of its allocations satisfy $\left.\mid q_{i}\right\rfloor$ $\leq a_{i} \leqq\left\lceil q_{i}\right\rceil$. Allocations not satisfying quota seem to violate common sense, and have proven to be politically subject to attack [17].

Aside from the fairness question, a method satisfying quota clearly is balanced, and--while not necessarily stable in the strict sense defined above--is almost stable in the sense that if any two parties with $\mathrm{a}^{*}$ and $\bar{a}$ seats coalesce, then the coalesced party receives $\mathrm{b}$ seats, where $\mathrm{a}^{*}+\overline{\mathrm{a}}-2 \leqq \mathrm{~b} \leqq \mathrm{a}^{*}+\overline{\mathrm{a}}+2$.

The Hamilton method $(H)$ clearly satisfies quota--indeed can be said to have been motivated by this desire. However, as we have seen, it violates two other basic principles. Aside from $\underset{\sim}{H}$, what other methods satisfy quota? The emphasis historically, particularly since Huntington's work, has been on divisor methods. However, none of these can satisfy quota. In fact, a subsequent result (Theorem 7) implies the following. 
Theorem 6. There exists no alzocation method that is monotone, consistent and satisfies quota.

Since these three properties seem to be essential ones, an immediate question is: what can be weakened in order to admit the existence of some method?

In the presence of monotonicity and satisfying quota it is reasonable to consider a slight weakening of consistency. Consider a method $\underset{\sim}{M}$ and let $\underset{\sim}{f} \in \underset{\sim}{M}$ with $f_{j}(\underset{\sim}{p}, h)=a_{j}$. Then party $j$ is said to be eligible at $\mathrm{h}+1$ for its $\left(a_{j}+1\right)$ st seat if $a_{j}+1 \leqq$ $\left\{p_{j}(h+1) / \sum_{i} p_{i}\right\} ;$ equivalently, $a_{j}<q_{j}(\underset{\sim}{p}, h+1)=p_{j}(h+1) / \sum_{i} p_{i}$, that is if party $j$ can be given an extra seat without exceeding upper quota. We say that a method $M$ is quota-consistent* if it is consistent as between eligible parties. More precisely, $\left(p^{*}, a\right)$ has weak eligible priority over $(\bar{p}, \bar{a})$ written $\left(p^{*}, a^{*}\right) \succsim^{e}(\bar{p}, \bar{a})$, if in some problem one party having $\mathrm{p}^{*}$ votes and $\mathrm{a}^{*}$ seats has weak priority over another party having $\bar{p}$ votes and $\bar{a}$ seats and both are eligible to receive another seat. If both $\left(\mathrm{p}^{*}, a^{*}\right) r^{\mathrm{e}}(\overline{\mathrm{p}}, \overline{\mathrm{a}})$ and $(\bar{p}, \bar{a}) \gtrsim^{e}\left(p^{*}, a^{*}\right)$ we write $\left(p^{*}, a^{*}\right) \sim^{e}(\bar{q}, \bar{a})$. For $M$ to be quota-consistent it is required that whenever $\left(p^{*}, a^{*}\right) \sim^{e}(\bar{p}, \bar{a})$ and both parties are eligible at $h+1$ but $\underset{\sim}{f}$ gives the $(h+1)$ st seat to the p*-party, then there is an extension of $\mathrm{f}_{\mathrm{N}}^{\mathrm{h}}$ giving the $(h+1)$ st instead to the $\bar{p}$-party.

The quota method $Q$ of allocation is the set of all solutions $\underset{\sim}{f}$ obtained recursively as follows:

(i) $f_{i}(\underset{\sim}{p}, 0)=0 \quad 1 \leqq i \leqq s$.

(ii) Let $a_{i}=f_{i}(\underset{\sim}{p}, h)$ be an allocation for $h$ of $\varrho$ and $E(h+1)$ the set of parties eligible to receive an extra seat at $h+1$. If $k \in E(h+1)$ is some one party for which

$$
p_{k} /\left(a_{k}+1\right) \geq p_{i} /\left(a_{i}+1\right) \text { for all } i \in E(h+1)
$$

then

$$
\left.f_{k}(\underset{\sim}{p}, h+1)=a_{k}+1, f_{i} \underset{\sim}{(p}, h+1\right)=a_{i} \text { for } i \neq k .
$$

${ }^{*}$ Called "consistent" in $[1,3]$. 
Theorem? [4]. Q is the unique allocation method that is house-monotone, quota-consistent and satisfies quota.

This theorem gives powerful reasons for acceptance of the quota method $Q$ for both problems of apportionment in majority systems and problems of allocation in proportional representation systems. In practice one finds that o has a tendency to produce solutions that round up the exact quotas of large parties more often than those of small parties. This seems reasonable for the application of $Q$ to proportional representation systems in that it inferentially asks for a "large" vote before according any representation at all. Notice, however, that no large party is allowed more seats than its upper quota. This same property might appear to cause a difficulty for the application of $\mathrm{Q}$ to apportionment problems, since in this situation it is usually necessary for each geographical entity to receive some minimum number of seats (e.g., 1 or 2). For this case the method $Q$ has an immediate generalization that allows the specification öf any desired "unbiased" minimum representations for districts, and a uniqueness theorem similar to Theorem 7 obtains [3].

\section{CONCLUSIONS}

This paper has addressed the problem of the allocation of integral representation to parties having vote totals in a proportional representation system. The principal point is that methods of allocation should not be chosen by bickering over numbers, nor, indeed, through ad hoc claims of various mechanical procedures, but rather by analysis of the properties of methods. The issue is to decide upon a method whose qualitative properties are equitable for the situation at hand. For proportional representation systems this analysis commends one of two methods: the quota method $\underset{\sim}{\mathrm{Q}}$ or the Jefferson method $\underset{\sim}{\mathrm{J}}$.

The Jefferson method claims recognition because it is monotone, consistent, balanced and encourages coalitions. Specifically, encouraging coalitions would seem to be precisely the type of stability desired for a body politic operating a proportional representation system. However, a major defect of $\mathrm{J}$ is that it fails the seemingly most common-sense test of satisfying quota. The Quota method merits recognition because it does satisfy quota, is consistent subject to that property, and is monotone and balanced. But it is only almost stable, and, in fact, does not necessarily encourage coalitions.

The choice between these methods of allocation should be made in terms of which criteria are viewed as most important for the situation in question. 
References

[1] Balinski, M.L., and H.P. Young, A New Method for Congressional Apportionment, Proceedings of the National Academy of Sciences, U.S.A., 71 (1974), 4602-4606.

[2] Balinski, M.L., and H.P. Young, On Huntington Methods of Apportionment, submitted for publication.

[3] Balinski, M.L., and H.P. Young, The Quota Method of Apportionment, American Mathematical Monthly, 82 (1975), 701-730.

[4] Bliss, G.A., E.W. Brown, L.P. Eisenhart, and R. Pearl, Report to the President of the National Academy of Sciences, 9 February 1929, in Congressional Record, 70 th Congress, 2nd Session, 70 (1929), 4966-4967.

[5] Congressional Record, 70th Congress, 2nd Session, 70 (1929), 1500 .

[6] Cotteret, J.M., and C. Emeri, Les systèmes eléctoraux, Presses Universitaires de France, Paris, 1970.

[7] Hamilton, Alexander, The Papers of Alexander Hamilton, Vol. XI (Eebruary 1792 - June 1972), Harold C. Syertt, ed., Columbia University Press, New York, 1966, $228-230$.

[8] d'Hondt, V., La représentation proportionnelze des partis par un électeur, Ghent, 1878.

[9] d'Hondt, V., Système pratique et raisonné de représentation proportionnelze, Muquardt, Brussels, 1882.

[10] Huntington, E.V., The Apportionment of Representatives in Congress, Transactions of the American Mathematical Society, $30(1928), 85-110$.

[11] Huntington, E.V., The Mathematical Theory of the Apportionment of Representatives, Proceedings of the National Academy of Sciences, U.S.A., I (1921), 123-127.

Jefferson, T., The Works of Thomas Jefferson, Vol. VI, Paul Leicester Ford, ed., G.P. Putnam and Sons, New York, 1904, 460-471.

[13] Morse, M., J. von Neumann, and L.P. Eisenhart, Report to the President of the National Academy of Sciences, 28 May, 1948. 
[14] U.S. Public Law 291, H.R. 2665, 55 stat. 761, 15 November, 1941.

[15] Sainte-Lagüe, La représentation et la méthode des moindres carrés, Comptes Rendus de l'Académie des Sciences, 151 $(1910), 377-378$.

[16] Seaton, C.W., Report to the Chairman of the Committee of the Census, 25 october 1881, in Apportionment Among the Several States, House of Representatives, $56 \mathrm{th}$ Congress, 2nd Session, Report No. 2130, 20 December 1900 .

[17] Webster, D., The Writings and speeches of Daniel Webster, Vol. VI, National Edition, Little, Brown and Company, Boston, Massachusetts, 1903, 102-123. 